\title{
Bronchopulmonary dysplasia: early diagnosis, prophylaxis, and treatment
}

\author{
Anne Greenough
}

Survival of extremely premature babies has improved considerably over the last decade. ${ }^{1}$ Unfortunately, however, many of these infants remain chronically dependent on respiratory support for many weeks or even months and the most severely affected develop bronchopulmonary dysplasia. ${ }^{2}$ The incidence of bronchopulmonary dysplasia among ventilated infants varies, depending on gestational age, from $4 \cdot 2 \%$ to as high as $40 \%,{ }^{13}$ but increases up to $70 \%$ among infants in whom it is necessary to prolong mechanical ventilation beyond two weeks. ${ }^{5}$ Such infants have an increased mortality and morbidity even after discharge from neonatal intensive care. Readmission is common during the first two years of life and infants suffer from recurrent respiratory symptoms with persistent lung function abnormalities. Thus it is most important to determine if the course of this disease may be altered and if it is preventable.

\section{Diagnosis}

Early diagnosis is desirable as this would facilitate institution of treatments before irreparable damage has taken place in the hope of altering the disease process. Bronchopulmonary dysplasia or chronic lung disease of prematurity is now diagnosed if infants remain dependent on respiratory support beyond a certain age, usually 1 month in association with an abnormal chest radiograph appearance. ${ }^{3}$ Unfortunately such criteria do not allow an early diagnosis. Possibly a more fruitful approach in this respect would be to use attainment of a positive finding from an investigation, if this were shown to be specific for the diagnosis of chronic lung disease of prematurity.

\section{(1) CHEST RADIOGRAPH}

Bronchopulmonary dysplasia has usually been diagnosed from the chest radiograph appearance. Northway originally described a progression of changes in the radiograph appearance which were divided into four stages. Stage IV, the most severe, appeared beyond 30 days of age and was associated with hyperexpansion and enlargement of cystic areas, particularly in the lower lobes. ${ }^{2}$ This appearance was thought then to be typical of persistent chronic lung disease of prematurity, but nowadays many infants who remain dependent on respiratory support after 1

Kings College School of Medicine and Dentistry, Denmark Hill, London SE5 8RX

Correspondence to: Dr Greenough disease of prematurity. ${ }^{6}$ Northway's stage IV bronchopulmonary dysplasia was then reclassified as type II chronic lung disease of prematurity. ${ }^{6}$ This differentiation into two types of chronic lung disease of prematurity among infants dependent on respiratory support at 1 month of age was useful, as the two groups had very different prognoses, type I was more common and usually resolved whereas type II usually followed pulmonary interstitial emphysema and had a poor prognosis. A logical use of terminology would be to restrict use of bronchopulmonary dysplasia to indicate a poorer prognosis - that is, those infants with type II chronic lung disease of prematurity. Other infants who remain dependent on respiratory support after 1 month of age, but have less severe chest radiograph changes, would be described as suffering from chronic lung disease of prematurity.

The appearance of the chest radiograph may be further categorised by use of scoring systems. At King's College Hospital we have developed such a scoring system, based on the lung volume and the presence and location of cystic and interstitial elements, which has enabled us to predict which infants will have continuing oxygen dependency at a postconceptional age of 36 weeks or the worst lung function abnormalities. Unfortunately, to date, such scoring systems have usually been based on the chest radiograph appearance at 1 month, and their usefulness regarding an early diagnosis has not been tested.

The chest radiograph appearance of Northway's stage I and II bronchopulmonary dysplasia, which classically appear before 1 month of age, unfortunately may be mimicked by severe respiratory distress syndrome, pneumonia, or heart failure and thus do not allow an early diagnosis. Such conditions may resolve, and thus institution of treatments directed at preventing chronic lung disease of prematurity are inappropriate, particularly those associated with side effects. The chest radiograph appearance associated with stage III bronchopulmonary dysplasia may also have an alternative diagnosis, delayed resolution of pulmonary interstitial emphysema. Both stage III bronchopulmonary dysplasia and persistent pulmonary interstitial emphysema, particularly if present in very immature infants, are both likely to progress to chronic oxygen dependency thus differentiating between these diagnoses in an infant older than 2 weeks of age is not important clinically. Thus persistence of cystic elements beyond the second week of life in very preterm infants could be used to define chronic lung disease of 
prematurity or at least indicate the need to institute preventative treatment or disease limiting strategies.

\section{(2) TRACHEAL ASPIRATES}

It has been claimed that cytology of tracheal aspirate may be more useful in facilitating early diagnosis of chronic lung disease of prematurity, ${ }^{7}$ as changes in the aspirate cytology are more advanced than the concurrent chest radiograph appearance. Indeed, this asynchrony has been confirmed by comparison of the chest radiograph appearance to changes in lung tissue at necropsy. ${ }^{89}$ Classification of aspirate cytology, obtained at the time of endotracheal tube toiletry, is based on the most advanced changes seen. Several groups have sought to separate such changes into distinct stages or classes (C Neave, V Masura. Department of pathology, Women and Infants Hospital, Providence, Rhode Island, 1980). ${ }^{7011}$ Class I is characterised by epithelial sloughing, evidence of the destructive process once the injury has stopped, this appearance is usually found between days 0 and 4 . Then follow changes which may be evidence of a reparative process with regeneration, scarring and remodelling, but residual damage may still be present depending on the severity of the injury. The following cytologies are characteristic of the sequence of changes in the aspirate: (i) class II (days 4-7) regenerative changes, metaplasia, and early repair of epithelial cells; (ii) transitional class II-III (days 6-12) moderate repair mixed with metaplasia and possible nuclear atypia; (iii) class III definite nuclear atypia and metaplastic cells; and (iv) class IV mature squamous metaplasia, nuclear atypia no longer present. The speed of progression through these classes appears to be dependent on the oxygen dose. ${ }^{8}$ The exact importance of these differences in cytological appearance remains controversial. It has been suggested that class III is synonymous with bronchopulmonary dysplasia and results from exposure to high inspired oxygen concentrations and has a variable outcome. ${ }^{10}$ Class IV is more severe, occurring in infants intubated for longer than $\mathbf{3 0}$ days or with prolonged exposure to oxygen, or both, and there is usually residual pulmonary deficit. Classes I, II, and the transitional class II-III are usually associated with restoration of normal pulmonary growth and function.

Interpretation of the cytology of tracheal aspirates, however, may be hindered because of non-representative sampling of exfoliated cells with imperfect cytological interpretation which makes it difficult to distinguish cellular degeneration from atypia. The presence of histiocytes in the aspirates is unhelpful in diagnosis, as they are present in most aspirates after day 3 and foamy histiocytes occur with use of intravenous intralipid or in congestive heart failure. The presence of neutrophils is more useful in differential diagnosis, although $90 \%$ of aspirates on day 4 contain neutrophils, the frequency usually declines to $43 \%$ on day 7 but both in transitional and class III it increases again to $85 \%$ from days $11-15$. Infants who sub- sequently developed bronchopulmonary dysplasia had a peak incidence of neutrophils at about day 7 which only gradually declined over the next month. Unfortunately neutrophils may also be present in the aspirate because of intercurrent pneumonia or necrotising tracheobronchitis. ${ }^{12}$

Lactosylceramide, an accurate marker of destructive lung inflammation, is strikingly raised in tracheal aspirates of infants who progress to bronchopulmonary dysplasia compared with those of controls when studied in the first week of life. ${ }^{13}$ Tracheal aspiration has also been used to document persisting inadequacy of the surfactant system ${ }^{14}$ and thus indicate infants who will develop bronchopulmonary dysplasia. In such infants the lecithin:sphingomyelin ratio increases only slowly and, ${ }^{15}$ in those in whom the condition is ultimately fatal, phosphatidylglycerol appears several months later than in infants who survive. In $50 \%$ of such infants no phospholipid could be detected in the tracheal aspirate collected at gestations corresponding to full term. A major drawback of any diagnostic technique based on tracheal aspirates, however, is that it is only possible to obtain representative sequential samples from intubated infants.

\section{(3) LUNG FUNCTION MEASUREMENTS}

Lung function measurements are now possible even in very preterm infants receiving intensive care and are useful in providing an acute assessment of treatment. ${ }^{16}{ }^{17}$ It has also been claimed such measurements, performed in the first week of life, may identify premature infants who will develop bronchopulmonary dysplasia. Although no difference in dynamic compliance could be demonstrated between infants who subsequently did or did not develop bronchopulmonary dysplasia, raised pulmonary resistance on day $1^{18}$ and total airways resistance at a mean age of 4.8 days ${ }^{19}$ was found in infants who later developed bronchopulmonary dysplasia compared with controls. The latter study, ${ }^{19}$ however, included infants of birth weight less than $750 \mathrm{~g}$ and both pulmonary and total airway resistance tend to reflect the size of central airways and thus the results may simply reflect the greater immaturity and lower birth weight of the infants with 'bronchopulmonary dysplasia' compared with the controls. There are many other problems in the interpretation of lung function measurements. Acute changes in lung function may be caused by airway inflammation, fluid overload, or concurrent medication, thus a single result may bear no relationship to the ultimate prognosis. Technical problems such as leaks around the endotracheal tube reduce the accuracy of the measurements. Many commercially available systems are very expensive and may calculate various measurements from pressure changes registered by oesophageal balloons, which are frequently inaccurate in sick preterm neonates, particularly those ventilated and at highest risk of bronchopulmonary dysplasia. 'Home made' systems, which avoid such problems by use of single breath techniques or alternative methods, require considerable expertise both to perform and interpret the 
measurements. Such factors will continue to prevent such lung function measurements becoming routine practice in neonatal intensive care units until their usefulness outside research studies is more fully proved.

\section{Prophylaxis}

A confident early diagnosis thus remains unusual, and prophylactic regimes must be assessed in those infants considered to be at high risk.

\section{(1) VITAMIN E AND SUPEROXIDE DISMUTASE} A number of agents have been given in an attempt to reduce oxygen related lung damage. Premature infants in the first 24 hours of life have inadequate concentrations of vitamin $E .^{20}$ Vitamin E deficiency enhances the toxic effects of oxygen upon the lung, which in animals may be prevented by vitamin $\mathrm{E}$ treatment. Unfortunately, although results of a non-controlled study were compatible with vitamin $\mathrm{E}$ reducing the incidence of infants with a chest radiograph appearance compatible with bronchopulmonary dysplasia, ${ }^{21}$ this finding has not been confirmed in randomised controlled trials. ${ }^{22}{ }^{23}$ Although a higher dosage regimen may be necessary to produce the desired therapeutic effect, this is not practical. Vitamin E decreases the oxygen dependent intracellular killing ability of neutrophils, resulting in a decreased resistance to infection ${ }^{24}$ and infants maintained at pharmacological concentrations of vitamin $\mathrm{E}$ have a significantly higher incidence of proved neonatal sepsis and necrotising enterocolitis. ${ }^{24}$

Human neonates are also deficient in superoxide dismutase, ${ }^{25}$ and pretreatment of rats with this substance prevents the toxic changes in lung macrophages exposed to hyperoxia ${ }^{26}$ and damage to lung cells. ${ }^{27} \mathrm{~A}$ dosage regimen of $0-25 \mathrm{mg} / \mathrm{kg}$ every 12 hours is tolerated in preterm infants without side effects. ${ }^{28} 29$ In a randomised controlled trial, superoxide dismutase compared with placebo significantly reduced clinical and radiological evidence of bronchopulmonary dysplasia. Infants given superoxide dismutase required less continuous positive airway pressure (CPAP) and hospitalisation compared with untreated controls. ${ }^{30}$ Superoxide dismutase was previously purified from bovine liver but is now produced from recombinant DNA techniques, although no toxicity has been reported it also theoretically could affect the bactericidal activity of polymorphonuclear cells.

\section{(2) VITAMIN A}

Vitamin A, administered in a randomised placebo controlled trial as 14 intramuscular injections over a 28 day period also resulted in lower incidence of bronchopulmonary dysplasia, and less need for supplemental oxygen, mechanical ventilation, and intensive care compared with controls. ${ }^{31}$ Preterm infants are likely to have low concentrations of vitamin $A$, because of deprived transplacental acquisition and inefficient parental administration because of photodegradation and absorption to the intra- venous tubing, but the exact requirement for vitamin $A$ is not precisely known. If the benefit of vitamin $A$ is confirmed and this treatment is to be given routinely, concentrations must be carefully monitored because of the side effects of this substance given in excess, particularly non-specific neurological abnormalities.

\section{(3) SURFACTANT}

Few surfactant studies have addressed the particular question as to whether surfactant treatment reduced bronchopulmonary dysplasia; those that have have yielded promising results. Human amniotic fluid surfactant given as rescue treatment to babies of between 24-29 weeks' gestational age was associated with a significant reduction in bronchopulmonary dysplasia. ${ }^{32}$ Larger doses of surfactant seem to be more useful, as a dosage regimen which incorporated doses of $120 \mathrm{mg}$ rather than $60 \mathrm{mg}$ of reconstituted bovine surfactant (surfactant TA) was more effective in preventing both bronchopulmonary dysplasia and intraventricular haemorrhage, although both doses had similar acute effects on improvements in oxygenation. ${ }^{33}$ To date no similar effects using calf lung surfactant or artificial lung expanding compound (ALEC) have been demonstrated.

\section{(4) RESPIRATORY SUPPORT}

Many authors have incriminated mechanical ventilation as a cause of bronchopulmonary dysplasia. An important method of prevention therefore would be to institute the least damaging form of ventilation. Unfortunately there have been very few studies which in a randomised fashion have compared the effectiveness of two forms of respiratory support with regard to lowering the incidence of bronchopulmonary dysplasia. One such study has recently been carried out, a multicentre randomised controlled trial tested the hypothesis that high frequency oscillation would be associated with a lower incidence of bronchopulmonary dysplasia. ${ }^{34}$ High frequency oscillation can provide a method of oxygenation at lower pressures than conventional ventilation in certain infants with severe respiratory failure and thus may be less damaging to the lungs. Unfortunately both conventional ventilation and high frequency oscillation were associated with similar high incidences of bronchopulmonary dysplasia, $40 \%$ and $41 \%$ respectively and worryingly high frequency oscillation increased the incidence of grade III and IV intraventricular haemorrhage and periventricular leucomalacia. ${ }^{34}$

Other forms of ventilation, patient triggered ventilation ${ }^{35}$ and continuous negative extrathoracic pressure (CNEP), have been used anecdotally with apparently good effect in respiratory distress syndrome but no randomised trials have been carried out to assess their role in reducing the incidence of bronchopulmonary dysplasia. It has been suggested early use of nasal CPAP and restricting the use of mechanical ventilation till relatively late in the course respiratory distress syndrome may be associated with a lower incidence of bronchopulmonary dysplasia. ${ }^{36}$ 
Unfortunately these data come from comparison of eight different centres, which were not randomised to different forms of respiratory support, and variations in the patient population or other management policies may have been responsible for the lower incidence.

A series of studies has demonstrated that ventilation at rates equal to or in excess of 60 breaths/minute, compared with slow rates, is associated with a reduction in pneumothorax which, like bronchopulmonary dysplasia, is related to barotrauma. ${ }^{37-39}$ Unfortunately no randomised trial has investigated whether fast rates will also reduce the incidence of bronchopulmonary dysplasia. One study apparently demonstrated that babies ventilated at fast frequencies had significantly worse lung function at follow up compared with those ventilated at conventional frequencies. ${ }^{40}$ They further suggested that the degree of lung impairment was related to the length of time spent at the faster rate. The study, however, had a number of impairments; only 14 infants were included, ventilator rates varied from $30-180 /$ minute, and the ventilators used are known to malfunction at fast rates. Using an appropriate ventilator, ${ }^{41}$ fast rates, by mimicking the infant's respiratory pattern will induce synchrony ${ }^{42}$ improving oxygenation and reduce carbon dioxide concentrations. ${ }^{43}$ As a consequence it is possible to reduce mean airway pressure at fast rates and it seems likely that this would be associated with a lower incidence of chronic lung disease of prematurity. At King's College Hospital our routine policy, if infants require ventilation beyond resuscitation, is to commence in the labour suite ventilator rates of 60 breaths/ minute. If respiratory efforts remain obvious then the rate is increased till they disappear and the infant is then presumed to be synchronous. ${ }^{44}$ If, despite rate manipulation, respiratory efforts remain obvious, the infant is then paralysed and rate reduced to $40-60 /$ minute to avoid airtrapping. ${ }^{45}$ Using such a strategy among ventilated very low birthweight infants the incidence of chronic lung disease of prematurity varies each year at King's College Hospital from $15 \%-20 \%$, this is despite ventilating up to 30 infants per year with birth weights less than $750 \mathrm{~g}$.

\section{Management}

(1) WEANING FROM MECHANICAL VENTILATION As respiratory support has been incriminated as an aetiological factor in the development of bronchopulmonary dysplasia, it is essential not only to reduce peak pressures and the inspired oxygen concentration to the therapeutic minimum, but also to wean infants from respiratory support as soon as possible. A variety of strategies have been tried. Limitation of inspiratory time to a maximum of 0.5 seconds throughout rate reduction is associated with a significantly shortened duration of weaning. ${ }^{46}$ Treatment with theophylline reduces the frequency and duration of respiratory pauses which occur in association with bronchopulmonary dysplasia, it improves diaphragmatic function, and reduces pulmonary artery pressure. Benefits regarding lung function which would facilitate weaning, however, have been demonstrated only in the first month of life. Theophylline has a synergistic action on lung function with diuretics $^{47}$ and can reduce the duration of weaning. 1648 Very few extremely preterm infants have been included in such studies and one demonstrated theophylline to be ineffective in ventilated infants older than 30 days of age, as extensive pulmonary fibrosis had resulted in irreversible airways obstruction. ${ }^{16}$ In older infants and children long term treatment with theophylline can be associated with multiple side effects including gastrointestinal upset and behavioural disturbance. In preterm infants tachycardia, vomiting, and gastro-oesophageal reflux are increased, as a consequence theophylline concentrations require careful and regular monitoring. This treatment should be restricted to infants in whom ventilator rate reduction has already commenced and thus are likely to wean from ventilation over a few days.

Steroid treatment is also associated with a number of actions which would be potentially beneficial in chronic lung disease of prematurity: reduction of pulmonary oedema, enhancement of surfactant synthesis, reduction of inflammation in injured small airways, and reduction of bronchospasm. A series of uncontrolled trials have indeed demonstrated that administration of steroids improved pulmonary function. ${ }^{49-51}$ In one randomised controlled trial improvements in respiratory rate, reduction in peak pressure, and inspired oxygen concentration were reported after a five day course. Two multicentre trials have investigated the impact of this treatment on weaning. The first reported an increase in weaning from respiratory support in ventilator dependent infants at 2 to 6 weeks of age in association with a $64 \%$ improvement in pulmonary compliance compared with only a 5\% improvement in the placebo group. ${ }^{52}$ Unfortunately no significant difference between the two groups was found in mortality or hospital stay, and as a sequential analysis was used only seven pairs of infants were recruited into the study. The second trial recently reported to the British Association of Perinatal Medicine, involved much larger numbers of infants, and confirmed that steroids hastened weaning from ventilator support but was not apparently associated with any benefits in long term outcome. Recent evidence suggests the relatively poor success of steroid treatment in previous trials is explained by the short duration of administration. ${ }^{53}$ Weaning from both ventilation and supplemental oxygen and in addition neurological outcome is improved in infants given a 42 day course of steroids compared not only with controls but also with those given an 18 day course of steroids. ${ }^{53}$

Steroid treatment, unfortunately, is associated with a number of side effects that may deter use of this treatment in infants with relatively mild chronic lung disease of prematurity. An increased incidence of pneumothorax, sepsis, necrotising enterocolitis, hyperglycaemia, and hypertension have been reported. The effect on immune function, however, is controversial $^{5455}$; a recent comparison of 
infants given a three week course of dexamethasone to controls found no increased incidence of sepsis. ${ }^{56} \mathrm{~A}$ potentially worrying complication, periventricular leucomalacia, has only been reported in one small series. ${ }^{57}$ The high incidence of side effects, and at present the limited success of steroids, suggests that this form of treatment should be restricted to ventilator dependent infants in whom no progress with weaning is being made. It is essential to exclude sepsis before commencing treatment and throughout treatment blood pressure must be carefully monitored. There is no evidence that repeated courses of steroids are successful and such a policy is likely to increase the risk of side effects. In infants at highest risk of ventilator damage, that is those of extreme prematurity, if no progress is being made in reduction of ventilator settings at two weeks, it seems reasonable to embark on a prolonged course of steroid treatment providing this is in association with careful monitoring for side effects. An appropriate dosage regimen consists of dexamethasone at $0.5 \mathrm{mg} / \mathrm{kg} /$ day for three days, followed by 0.3 $\mathrm{mg} / \mathrm{kg} /$ day for a further three days, and then $0 \cdot 1$ $\mathrm{mg} / \mathrm{kg} /$ day for at least two weeks. The precise length the lowest steroid dosage should be maintained remains uncertain, but we have certainly seen acute electrolyte disturbance if the course is terminated too abruptly.

There is a small group of very preterm infants who, despite improvements in their respiratory status, almost immediately require reventilation after extubation with the development of a mixed respiratory and metabolic acidosis. Often no obvious cause is found, but the infants are usually very immature with poor respiratory effort and relatively low muscle mass. After the second such episode we electively continue ventilation at a low rate until the infant is regularly gaining weight and use achievement of a weight milestone (usually $1.0 \mathrm{~kg}$ ) as criteria for extubation. It has been suggested that CNEP might provide an alternative form of respiratory support in such babies and has the advantage of not involving intubation. Unfortunately, despite recent improvements to the neck seal designed by the Brompton group, there are still problems encountered during CNEP, particularly in the very small infant: poor temperature control, limited access, and facial oedema. No randomised study has been carried out to substantiate if CNEP in this situation has any long term advantage over intermittent mandatory ventilation.

\section{(2) BRONCHODILATORS}

Wheezy infants in the first year of life, who were born at term, apparently infrequently show acute benefit from bronchodilators. ${ }^{58}$ The response of preterm infants, however, may be different, and those with chronic lung disease of prematurity who have been mechanically ventilated with high inspired oxygen concentrations have morphologic evidence of peribronchiolar smooth muscle hypertrophy. ${ }^{59}$ Administration of inhaled bronchodilators to preterm infants during intensive care has indeed been associated with an improvement in lung function. Inhaled isoprenaline causes a reduction in airways resistance and improvement in conductance when given to infants with chronic lung disease at term. ${ }^{60}$ Inhaled salbutamol and ipratropium bromide both resulted in similar improvements in lung function, ${ }^{61}$ and terbutaline given subcutaneously reduced wheeze as evidenced by an increase in the inspiratory:expiratory ratio. These studies, however, documented improvements in lung function only over, at maximum, one hour and these improvements were not associated with changes in blood gases. The benefits of maintenance treatment with bronchodilators for infants still receiving intensive care remains to be proved. At follow up, however, regular inhaled terbutaline given via a simple spacer device, a coffee cup, reduces symptoms and improves lung function in preterm infants with recurrent cough and/or wheeze, ${ }^{62}$ suggesting maintenance treatment during intensive care may be beneficial. Results from follow up studies have demonstrated that it is important to treat only symptomatic infants rather than those with asymptomatic lung function abnormalities. We have recently documented that, whereas nebulised ipratropium bromide acutely improves lung function among symptomatic preterm infants in the first two years of life, it causes a deterioration in airways resistance among infants who have asymptomatic lung function abnormalities.

Despite alterations in the osmolality and $\mathrm{pH}$ of the nebuliser solution and removal of the preservative, nebulised treatment has been reported to still cause an acute deterioration in lung function in certain infants born at term. ${ }^{63}$ These episodes may be due to bronchomalacia, which is likely to be more common in the preterm infant. In the presence of bronchomalacia, bronchodilator treatment could acutely cause airway collapse and hence result in a deterioration in lung function. It thus seems prudent to restrict treatment with nebulised bronchodilators during intensive care to preterm infants who are obviously wheezy. Ipratropium bromide and salbutamol appear equally effective in the treatment of such infants, both in the acute phase $^{61}$ and at follow up. ${ }^{62}$

\section{(3) DIURETICS}

Diuretic treatment is also associated with short term improvements in lung function in ventilator dependent infants. Frusemide causes improvements in lung compliance and airways resistance, ${ }^{17} 64$ reduction in ventilator requirements, ${ }^{65}$ and transitory (two hours) improvements in blood gases. ${ }^{17}$ Similar short term rapid improvements in lung function are produced by intravenous diuretic treatment in chronic non-ventilator dependent infants. ${ }^{66}$ Maintenance treatment has also been shown to be useful, improving compliance, resistance, and oxygenation at 1 week of age ${ }^{67}$ Chronic use of frusemide unfortunately, however, is associated with a number of side effects, the most important being hypercalcuria, renal calcification, and nephrolithiasis.

It has been suggested that as many as $48 \%$ of infants receiving chronic frusemide treatment 
over an average of 48 days develop renal calcification. The risk is greatest in the most immature infants, those receiving treatment by the intravenous route and for the longest duration. Although the renal calcification and calculi may initially be asymptomatic, infants on this treatment for longer than two weeks should have regular renal ultrasound examinations to facilitate early diagnosis. Renal calcification usually disappears once frusemide is discontinued, and chlorothiazide is beneficial as it reduces urinary calcium excretion, ${ }^{68}$ which is associated with dissolution of the calculi. Frusemide treatment is associated with other complications including secondary hyperparathyroidism, rickets, ototoxicity, metabolic alkalosis, and hypochloraemia. Metabolic alkalosis in adults may result in hypoventilation and hypercarbia, but this can be prevented by provision of extra chloride. Ototoxicity is also theoretically preventable as it is related to the plasma concentration of frusemide; unfortunately, however, aminoglycosides have a synergistic action on this side effect.

The thiazide diuretics are potassium sparing and chlorothiazide in particular reduces calcium excretion and thus may be useful in the treatment of hypertensive infants with chronic lung disease of prematurity. ${ }^{69}$ These diuretics are less acutely effective than frusemide as their diuretic action is not evident for three to five days after initiating treatment. Maintenance treatment, however, with hydrochlorothiazide and spironolactone may improve outcome, ${ }^{70}$ for although no difference in the number of hospital or ventilator days was demonstrated, total respiratory compliance was increased after four weeks of diuretic treatment compared with controls. Commencement of this combination of diuretics in the first weeks of life was also associated with a significant improvement in survival.

Improved knowledge of the action, benefit, and side effects of the various diuretics in preterm infants allows a treatment policy to be drawn up. Frusemide treatment should be restricted to the acute management of fluid overload, particularly in ventilator dependent infants and its use reviewed on a daily basis. Infants chronically diuretic dependent-for example, those in incipient right heart failureshould be maintained on chlorothiazide and spironolactone administered orally.

(4) INFECTION

Infants with chronic lung disease are frequently colonised with bacteria, particularly pseudomonas, although the 'resident' bacteria varies between neonatal intensive care units. Identification of bacteria on microscopy of tracheal aspirate alone is thus not an indication for antibiotic treatment, but rather deterioration in respiratory state in association with both a change in the nature of secretions from the endotracheal tube and the chest radiograph appearance should be the criteria for commencing treatment. The open door policy of visiting practised on most neonatal units means that infants are exposed to many different types of infection including those due to atypical organ- isms and viruses. To launch a full range of bacterial and viral investigations on each occasion an infant with chronic lung disease of prematurity has a deterioration in respiratory state is clearly impractical. Failure to identify bacteria in the tracheal aspirate during such a change in the infant's condition should prompt at least a nasopharyngeal aspirate to be sent for immunofluorescence to identify respiratory syncytial virus, as treatment with ribavirin seems useful in infants positive for respiratory syncytial virus. Whether other viral infections are important in causing such episodes or if ribavirin would be useful in treating infants with chronic lung disease of prematurity so infected is not known, but is at present under investigation at King's College Hospital. Frequently, bacterial infection is strongly suspected but remains unproved, under such circumstances limiting the duration of antibiotic treatment to a five day course seems appropriate. Infants may suffer from many such episodes and unless an organism is isolated, alternating the choice of antibiotic or antibiotics may avoid the development of resistant organisms. Infants who do not respond to the usual antibiotic combinations and from whom no bacteria or virus is isolated, may show improvement if a prolonged course of cotrimoxazole and erythromycin is instituted.

The high incidence of chronic lung disease of prematurity, particularly in very preterm infants, highlights this as an area essential for research, not only to improve our acute management of affected infants, but most importantly to develop more effective preventative strategies. The results from surfactant replacement treatment are extremely encouraging but it seems likely, despite this tool, we will always have to provide some method of respiratory support at least for the very immature infants. Thus it is essential, if we are to make a major impact on the incidence of chronic lung disease of prematurity, that further research is performed to facilitate tailoring respiratory support more accurately for the requirements of the very preterm infant.

1 Greenough A, Roberton NRC. Morbidity and mortality in neonates ventilated for the respiratory distress syndrome. Br Med F 1985;290:597-600.

2 Northway WH Jr, Rosal RC, Porter DY. Pulmonary disease following respirator therapy of hyaline membrane disease: bronchopulmonary dysplasia. N Engl f Med 1967;276 357-68.

3 Bancalari E, Gerhardt T. Bronchopulmonary dysplasia. Pediatr Clin North Am 1986;33:1-23.

4 Reynolds EOR, Taghizadeh A. Improved prognosis of infants mechanically ventilated for hyaline membrane disinfants mechanically ventilated for hy

5 Ariagno RL. Use of steroids. In: Merrit A, Northway WH, Boynton BR, eds. Bronchopulmonary dysplasia. Boston: Boynton BR, eds. Bronchopulmonary dysplasia.

6 Hyde I, English RE, Wilhams JA. The changing pattern of chronic lung disease of prematurity. Arch Dis Child 1989;

7 D'Ablang G, Bernard B, Zahavov I, Barton L, Kaplan B, Schwinn CP. Neonatal pulmonary cytology and bronchoSchwinn CP. Neonatal pulmonary cytology and bronchopulmonary dysplasia. Acta Cytol (Baltimore) 1975;19:21-7.

Rosan RC. Hyaline membrane disease and a related spectrum of neonatal pneumopathies. Perspect Pediatr Pathol 1975;2:

9 Edwards DK, Dyer WM, Northway WH. Twelve years' experience with bronchopulmonary dysplasia. Pediatrics 1977;59:839-46.

10 Merritt TA, Stuard ID, Puccia J. Newborn tracheal aspirate cytology: classification during respiratory distress syn- 
drome and bronchopulmonary dysplasia. 7 Pediatr 1981 98:949-55.

11 Doshi N, Canbour A, Fujikura T, Klionsky B. Trachea aspiration cytology in neonates with respiratory distress:
histopathologic correlation. Acta Cytol (Baltimore) 1982;26: 15-21.

12 Sherman MP, Goetzman BW, Ahlfors CE, Wennberg RP Tracheal aspiration and its clinical correlates in the diagnosis of congenital pneumonia. Pediatrics 1980;65:258-63.

13 Hallman M, Pitkanen O, Rauvala H, Merritt TA. Glycolipid accumulation in lung effluent in bronchopulmonary dysplasia. Pediatr Res 1987;21:454A.

14 Obladen M. Alterations in surfactant composition. In: Merrit A, Northway WH, Boynton BR, eds. Bronchopulmonary dysplasia. Boston: Blackwell Scientific Publications,
1988:131-41.

15 Hallman M, Spragg R, Harrell JH, Moser KM, Gluck L. Evidence of lung surfactant abnormality in respiratory failure. $\mathcal{f}$ Clin Invest 1982;70:673-83.

16 Rooklin AR, Moomjiian AS, Fox WW. Theophylline therapy in bronchopulmonary dysplasia. F Pediatr 1979;95:882-4.

17 Kao LC, Warburton D, Sargent CW, Platzker ACG, Keens TG. Furosemide acutely decreases airway resistance in chronic bronchopulmonary dysplasia. $\mathcal{F}$ Pediatr 1983;103: 624-9.

18 Desai NS, Cunningham MD, Boyer DJ, et al. Predisposing pulmonary dynamics from birth for infants with bronchopulmonary dysplasia. Clin Res 1983;31:908A.

19 Goldman SL, Gerhardt T, Sonni R, et al. Early prediction of chronic lung disease by pulmonary function testing. f Pediatr 1983;102:613-7.

20 Moyer WJ. Vitamin $\mathrm{E}$ levels in term and premature newborn infants. Pediatrics 1950;6:893-6.

21 Ehrenkranz RA, Bonta BW, Ablow RC, Warshaw JB. Amelioration of bronchopulmonary dysplasia following vitamin $\mathrm{E}$ administration. A preliminary report. $N$ Engl f Med 1978;299:564-8.

22 Ehrenkranz RA, Ablow RC, Warshaw JB. Prevention of bronchopulmonary dysplasia with vitamin $\mathrm{E}$ administration during the acute stages of respiratory distress syndrome. during the acute
Pediatr $1979 ; 95: 873-8$.

23 Saldanha RL, Cepeda EE, Poland RL. The effect of vitamin $\mathrm{E}$ prophylaxis on the incidence and severity of bronchopulmonary dysplasia. $f$ Pediatr 1982;101:89-93.

24 Johnson L, Bowen FW, Abbasi S, et al. Relationship of prolonged pharmacologic serum levels of vitamin $E$ to incidence of sepsis and necrotizing enterocolitis in infants with birth weight 1,500 grams or less. Pediatrics 1985;75: 619-38.

25 Frank L, Lewis P, Sosenko I. Dexamethasone stimulation of fetal rat lung antioxidant enzyme activity in parallel with surfactant stimulation. Pediatrics 1985;75:569-74

26 Simon $L$. Protection against toxic effect of sustained hyperoxia on lung macrophages by superoxide dismutase. Clin Res 1980;28:432A

27 Block ER, Fisher AB. Protection of hyperoxic induced depression of pulmonary serotonin by pre-treatment with superoxide dismutase. Am Rev Respir Dis 1977;116:441-6.

28 Rosenfeld W, Evans H, Jhaveri R. Safety and plasma concentrations of bovine superoxide dismutase administered to human premature infants. Developmental Pharmacology and Therapeutics 1982;5:151-61.

29 Rosenfeld W, Sadhev S, Zabalera I, Jhaveri R. Measurement of superoxide dismutase in neonates utilising polyclonal of superoxide dismutase in neonates
antibodies. Pediatr Res 1986;20:209A.

30 Rosenfeld W, Evans H, Concepcion L, Jhaveri R, Schaeffer $M$, Friedman A. Prevention of bronchopulmonary dysplaM, Friedman A. Prevention of bronchopulmonary dyspla-
sia by administration of bovine superoxide dismutase in preterm infants with respiratory distress syndrome. f Pediatr 1984;105:781-5.

31 Shenai JP, Kennedy KA, Chytil F, Stahlman MT. Clinical trial of vitamin A supplementation in infants susceptible to bronchopulmonary dysplasia. $\mathcal{F}$ Pediatr 1987;111:269-77.

32 Hallman M, Merritt TA, Jarvenpaa A-L. Exogenous human surfactant for treatment of severe respiratory distress syndrome: a randomised prospective clinical trial. $\mathcal{f}$ Pediat 1985;106:963-9.

33 Konishi M, Fujiwara T, Naito N, et al. Surfactant replacement therapy in neonatal respiratory distress syndrome: a multi-centre, randomised clinical trial. Comparison of high vs low dose of surfactant TA. Eur $\mathcal{F}$ Pediatr 1988;147:20-5.

34 HIFI Study Group. High frequency oscillating ventilation compared with conventional mechanical ventilation in the treatment of respiratory failure in preterm infants. $N$ Engl treatment of respiratory

35 Mitchell A, Greenough A, Hird MF. Limitations of neonatal patient triggered ventilation. Arch Dis Child 1989;64: 924-9.

36 Avery ME, Tooley WH, Keller JB, et al. Is chronic lung disease in low birth weight infants preventable? A survey of 8 centres. Pediatrics 1987;79:26-30.

37 Bland RD, Kim MH, Light MJ. High frequency mechanical ventilation in severe hyaline membrane disease: and alterventilation in severe hyaline membrane disease:
native therapy? Crit Care Med 1980;8:275-80.

38 Greenough A, Dixon A, Roberton NRC. Pulmonary interstital emphysema. Arch Dis Child 1984;59:1046-105

39 Heicher DA, Kasting DS, Richards JR. Prospective clinical comparison of two methods for mechanical ventilation of neonates: rapid rates and short inspiratory time versus slow rate and long inspiratory time. $\mathcal{F}$ Pediatr 1981;98:957-81.

40 Robinson MJ, Maayan C, Eyal FG. Does the pattern of ventilation determine the degree of lung damage following inten-
sive care of the newborn? Isr $\mathcal{F}$ Med Sci 1982;18:835-9.

41 Greenough A, Greenall F. Performance of respirators at fast rates commonly used in neonatal intensive care unit. rates commonly used in neonat.

42 Greenough A, Greenall F, Gamsu H. Synchronous respiration - which ventilator rate is best? Acta Paediat Scand 1987;76:713-8.

43 Greenough A, Pool J, Greenall F, Morley CJ, Gamsu H. Comparison of different rates of artificial ventilation in preterm neonates with the respiratory distress syndrome. Acta Paediatr Scand 1987;76:706-12.

44 Greenough A, Milner AD. High frequency ventilation in the neonatal period. Eur $\mathcal{f}$ Pediatr 1987;146:446-9.

45 Hird M, Greenough A, Gamsu HR. Gas trapping during high frequency positive pressure ventilation using conventional ventilators. Early Hum Dev 1990;22:51-6.

46 Greenough A, Pool J, Gamsu H. A randomised controlled trial of two methods of weaning from high frequency posi-
tive pressure ventilation. Arch Dis Child 1989;64:834-8.

47 Kao LC, Durand DJ, Phillips BL, et al. Oral theophylline and diuretics improve pulmonary mechanics in infants with

48 Greenough A, Elias Jones A, Pool J, Morley CJ, Davis J. The therapeutic actions of theophylline in preterm ventilated therapeutic actions of theophylline in pre

$49 \mathrm{Kramer} \mathrm{LI}$, Hultzen C. The role of steroids in early bronchopulmonary dysplasia (BPD). Pediatr Res 1978;12:564A. 50. Donn SM, Faix RG, Banagale RC. Dexamethasone for bronchopulmonary dysplasia. Lancet 1983;ii:460.

51 Pomerance JJ, Puri A. Treatment of severe neonatal bronchopulmonary dysplasia with dexamethasone. Pediatr Res 1982;16:359A.

52 Avery GB, Fletcher AB, Kaplan M, Brudno DS. Controlled trial of dexamethasone in respirator-dependent infants with BPD. Pediatrics 1985;75:106-11.

53 Cummings JJ, D'Eugenio DB, Gross SJ. A controlled trial of dexamethasone in preterm infants at high risk for bronchopulmonary dysplasia. $N$ Engl f Med 1989;320:1505-10.

54 Gunn T, Reece ER, Metrakos K, Cole E. Depressed T cells following neonatal steroid treatment. Pediatrics 1981;67: 61-7.

55 Fitzhardinge PM, Eisen A, Lejtenyi C, Metrakos K, Romsay $M$. Sequelae of early steroid administration to the Romsay M. Sequelae of early steroid adminis

56 Ng PC, Thomson MA, Dear PRF. Dexamethasone and infection in preterm babies: a controlled study. Arch Dis Child tion in preterm

57 Noble-Jamieson CM, Regev R, Silverman M. Dexamethasone in neonatal chronic lung disease: pulmonary effects and intracranial complications. Eur $\mathcal{f}$ Pediatr 1989;148 365-7.

58 Lenney W, Milner AD. At what age do bronchodilator drugs work? Arch Dis Child 1987;53:532-5

59 Bonikos DS, Bensch KG, Northway WH Jr. Oxygen toxicity in the newborn: the effect of chronic continued 100 per cen oxygen exposure on the lungs of the newborn. Am $\mathcal{f}$ Patho 1976;85:623-50.

60 Kao LC, Warburton D, Platzker ACG, Keens TG. Effect of isoproterenol inhalation on airway resistance in chronic

bronchopulmonary dysplasia. Pediatrics 1984;73:509-14. ilkie RA, Bryan MH. Effect of bronchodilators on airway resistance in ventilator-dependent neonates
lung disease. $\mathcal{f}$ Pediatr 1987;111:278-82.

62 Yung disease. F Pediatr 1987;111:278-82. lator therapy by a simple spacer device for wheezy prema-
ture infants in the first two years of life. Arch Dis Child ture infants in

63 O'Callagan C. Milner AD, Swarbrick A. Paradoxical deterioration in lung function after nebulised salbutamol in deterioration in lung function after nebulis

64 Najak ZD, Harris EM, Lazzara A, Pruitt AW. Pulmonary effects of furosemide in preterm infants with lung disease. f Pediatr 1983;102:758-63.

65 McCann EM, Lewis K, Deming DD, Donovan MJ, Brady JP. Controlled trial of furosemide therapy in infants with chronic lung disease. $\mathcal{f}$ Pediatr 1985;106:957-62.

66 Kao LC, Warburton D, Cheng MH, Cedeno C, Platzker ACG, Keens TG. Effect of oral diuretics on pulmonary mechanics in infants with chronic bronchopulmonary dysplasia: results of a double-blind crossover sequential trial. Pediatrics 1984;74:37-44.

67 Engelhardt B, Elliott S, Hazinski TA. Short- and long-term effects of furosemide on lung function in infants with bron chopulmonary dysplasia. $\mathcal{f}$ Pediatr 1986;109:1034-9.

68 Hufnagle KG, Khan SN, Penn D, Cacciarelli A, Williams P. Renal calcification: a complication of long term frusemide
therapy in premature infants. Pediatrics 1982;70:360-3.

69 Abman SH, Accurso FJ, Koops BL. Experience with home oxygen in the management of infants with bronchopulmonoxygen in the management of infants with
ary dysplasia. $\mathcal{F}$ Pediatr 1984;23:471-6.

70 Albersheim SG, Solimano AJ, Sharma AK, et al. Randomised double blind controlled trial of long term diuretic therapy 615-20. 